\title{
EDITORIAL
}

\section{The improbability of an insignificant 'P' value?}

\author{
Stuart M. Hamilton. MD, FrCSC, Alan B.R. Thomson, MD, PhD, FRCPC, FACP
}

G RAM-NEGATIVE NOSOCOMIAL PNEUMONIA MAY RESULT from retrograde colonization of the pharynx from the stomach, and this may be more likely when the gastric $\mathrm{pH}$ is relatively high. Driks and colleagues (1) concluded that "in pariants receiving mechanical ventilation, the use of a prophylactic agent against stress-ulcer bleeding that preserves the natural gastric acid barrier against bacterial overgrowth may be preferable to antacids and $\mathrm{H}_{2}$ blockers".

The possibility of using sucralfate for prophylactic treatment of stress ulcers has called for th the battle cry 'first do no harm' in a signed editorial in The Canadian Journal of Surgery. Indeed. Dr MacLean suggests that "the results to date strongly suggest that this breakthrough will have wide application in the treatment of seriously ill patients" (2). What, then, is the improbability of an insignificant $P$ value?

Hospital acquired pneumonia is frequently caused by Gramnegative bacilli and usually results from aspiration of bacteria from the oropharynx arising during acute or chronic illnesses, previous use of antibiotics, endotracheal intubation or retrograde pharyngeal colonization by organisms from the stomach. Antacids or $\mathrm{H}_{2}$ receptor antagonists are often used in an intensive care unit setting for the trauma or multiple system disease patient to reduce the risk of upper gastrointestinal tract hemorrhage. These agents raise the intragastric $\mathrm{pH}$ and may be associated with an increase in Gram-negative bacilli in the gastric contents and thereby, at least on a theoretical basis, increase the risk of nosocomial pneumonia as a result of retrograde colonization of the pharynx.

Departments of Surgery and Medicine, University of Alberta, Edmonton, Alberta

Correspondence and reprints: Dr A.B.R. Thomson, 519 Robert Newton Research Building, University of Alberta. Edmonton, Alberta T6G 2C2
In the study of Driks and co-workers (1), patients admitted to the surgical, medical or coronary intensive care units who had been intubated within the previous $24 \mathrm{~h}$, were receiving mechanical ventilation and had a nasogastric tube in place, were eligible for study. Patients were excluded if they had active upper gastrointestinal tract hemorrhage, had received antacids, $\mathrm{H}_{2}$ blockers or sucralfate within the previous $48 \mathrm{~h}$, or had not received mechanical ventilation for more than 24 h. Patients were randomly assigned to prophylaxis with sucralfate $1 \mathrm{~g}$ every $6 \mathrm{~h}$ suspended in $20 \mathrm{~mL}$ of sterile water administered by nasogastric tube, or to conventional therapy with antacids, $\mathrm{H}_{2}$ blockers or both antacids and $\mathrm{H}_{2}$ blockers. The dose of these was not specified although standard regimens of various antacid preparations were administered. Similarly, standard doses of intravenous cimetidine or ranitidine were prescribed. It is presumed that these were given by bolus rather than by the more optimal route of continuous intravenous infusion (1).

Nasogastric aspirates were examined for bright red blood, 'coffee grounds' material or occult blood as detected by the guaiac test. Ventilator associated pneumonia was diagnosed if a chest film showed a new and persistent infiltrate that was consistent with pneumonia for at least three of the following findings: purulent sputum that showed more than 25 leukocytes on Gram staining, less than 10 squamous epithelial cells per low power field, and numerous bacteria per oil immersion field; an important respiratory or nosocomial pathogen isolated from culture of a tracheal aspirate; peripheral leukocytosis of more than 10,000 cells $/ \mathrm{mm}^{3}$; and fever (temperature above $38^{\circ} \mathrm{C}$ ).

Sputum samples and gastric aspirates were collected according to standard procedures, samples of gastric aspirates were tested with $\mathrm{pH}$ paper and aerobic bacteria were identified 
according to routine methods. In some patients, quantitative and qualitative analysis of aerobic bacteria present in the stomach, pharynx and trachea were undertaken. Isolates were characterized by results of Gram staining and colony morphologic studies and quantitative analysis were performed for Gramnegative bacilli only. The characteristics of the two treatment groups were compared by means of Student'st test for continuous variables with Fisher's exact test (two-tailed) for categorical variables. Quantitative levels of gastric, pharyngeal and tracheal colonization were compared with use of the Wilcoxon rank sum test adjusted for ties. Rates of pneumonia and mortality in the two groups were compared in terms of relative risks with $95 \%$ confidence intervals.

The two treatment groups were similar in terms of demographic characteristics and severity of illness on admission to the study. Of the 130 study patients, 61 received sucralfate and 69 received antacids or $\mathrm{H}_{2}$ blockers. In all, 39 patients received antacids, 17 received $\mathrm{H}_{2}$ blockers (cimetidine or ranitidine) and 13 received both an $\mathrm{H}_{2}$ blocker and antacids.

The distribution of underlying diseases, indications for intubation and surgical procedures according to site were similar in the two groups. Two patients in the sucralfate group and one patient in the antacid- $\mathrm{H}_{2}$ group had evidence of bright red blood in the nasogastric aspirate. One of the sucralfate treated patients died from massive gastrointestinal bleeding despite numerous transfusions and despite later use of ranitidine. The other patient in the sucralfate group, who had a small amount of bright red blood in the nasogastric aspirate, was switched to intravenous ranitidine with no further bleeding. The one patient treated with ranitidine who developed bright red blood did well with the bleeding subsiding after antacids were added.

Endoscopy was not performed in the patients so that the adequacy of sucralfate versus antacid- $\mathrm{H}_{2}$ for the prevention of gastric stress erosions could not be assessed. However, $16.4 \%$ of the sucralfate patients had occult blood in the nasogastric aspirate compared with $34.8 \%$ in the antacid- $\mathrm{H}_{2}$ group, yet $6.6 \%$ of the sucralfate group had 'coffee grounds' and $3.3 \%$ had bright red blood; figures for the antacid- $\mathrm{H}_{2}$ group were $1.4 \%$ and $1.4 \%$, respectively.

Significantly more patients in the antacid- $\mathrm{H}_{2}$ group had colonization with Gram-negative bacilli from the gastric aspirate, pharyngeal swab and tracheal aspirate. What was the clinical importance of the greater percentage of Gram-negative bacilli colonization of these aspirates? The rate of development of pneumonia in all patients was significantly lower in those treated with sucralfate than with antacid (seven of 61 patients [ $11.5 \%$ ] versus 16 of 69 patients [23.2\%], $\mathrm{P}=0.11$ ). and there was a lower mortality rate in the sucralfate treated patients ( 18 of 61 patients, [29.5] versus 32 of 69 patients [46.4\%], sucralfate versus antacid- $\mathrm{H}_{2}$ group, $\mathrm{P}=0.07$ ).

However, while this analysis was performed on 'intention to treat principle, in which all comers were analyzed, there were two patients in whom pneumonia developed three and eight days after their treatment with sucralfate. These subjects were subsequently switched to antacids. If the data are examined, excluding these crossover patients (ie, patients treated with sucralfate and subsequently treated with antacidsl then the differences between the sucralfate and the antacid-H group for development of pneumonia and for mortality rate: became statistically significant. The results of comparin sucralfate versus the antacid- $\mathrm{H}_{2}$ group for development pneumonia is as follows: $9.1 \%$ versus $23.2 \%$, respectivel $P=0.05$; for mortality the results are $23.6 \%$ versus $46.4 \%$ $\mathrm{P}<0.05$ ) (1). Other workers have also demonstrated muc lower rates of development of nosocomial pneumonia in pa tients receiving mechanical ventilation assigned to sucralfat rather than to antacids (3).

If our perspective is one of 'first do no harm', then one mus ask the question of whether antacids or $\mathrm{H}_{2}$ receptor antage nists are useful in preventing stress ulceration. The routin use of antacids or $\mathrm{H}_{2}$ blockers in the intensive care unit based on a number of excellent studies $(4,5)$, and antacid and cimetidine appear to be equally effective in reducing the incidence of bleeding and the requirement for transfusior (6).

Sucralfate has been studied for the prevention of stress ulcer ation (3.7-9). In one study six patients in the sucralfate group developed coffee grounds or bright red blood and one patien died, whereas only two patients in the antacid- $\mathrm{H}_{2}$ group had coffee grounds or bright red blood and there was no evidence of upper gastrointestinal bleeding (9). These differences ar not statistically significant. One cannot make the judgement therefore, that the sucralfate group is comparable to the antacid- $\mathrm{H}_{2}$ group for the prevention of stress ulcers because endoscopies were not performed to determine whether, i fact, stress ulcers developed; no placebo group was include so that the sucralfate group may be as good or as bad as the antacid- $\mathrm{H}_{2}$ group; the antacid- $\mathrm{H}_{2}$ group was clearly a heter geneous population.

This heterogeneous population comprised 69 patients, 3 receiving antacids, not all of whom were $\mathrm{pH}$ monitored ensure that the intragastric $\mathrm{pH}$ was at least $4 ; 17$ receiving $\mathrm{H}_{2}$ blockers (cimetidine or ranitidine), although the dose or the numbers of patients in each of the two different $\mathrm{H}_{2}$ recepto antagonist groups is unknown; and finally 13 patients receiv ing both an $\mathrm{H}_{2}$ blocker and antacids.

Thus, it is unclear whether sucralfate prevented stress ulcer in this study, and the study was not properly designed to deter mine whether the prevalence of clinically important bleeding episodes was different between sucralfate and either antacid or a single $\mathrm{H}_{2}$ receptor antagonist. Furthermore, it has beet demonstrated that infusion of $\mathrm{H}_{2}$ receptor is superior to bolu. injection for the prevention of stress ulcers and bleeding, st that the optimal dose and route of administration of $\mathrm{H}_{2}$ blockers was not achieved. Therefore, while one heartily agrees with the concept of doing no harm, one also wishes to do some good!

It is accepted that the rates of pneumonia and mortalit among patients treated with sucralfate were lower than in the antacid- $\mathrm{H}_{2}$ group. The authors correctly point out that, with the data available, it is difficult to isolate the effects of pneu. monia from factors such as the patient's medical condition and underlying disease (9). Furthermore, the percentage rate 
of pneumonia development in patients treated with either sucralfate or antacid- $\mathrm{H}_{2}$ blocker was much lower in this group than in previous studies published by these authors. They considered that this "most likely reflects selection of patients with less acute illness who did not require the addition of antacid to elevate gastric $\mathrm{pH}^{\prime \prime}(9)$. Enteral feeding also increases gastric $\mathrm{pH}$ and may increase the risk of nosocomial pneumonia (10). The number of patients receiving enteral feeding is not stated in the article although it was noted that one patient in the sucralfate group had pneumonia during tube feeding and also had an elevated gastric $\mathrm{pH}$.

I would certainly agree with the reviewer's suggestion that a randomized study would be needed to assess accurately the risk associated with different regimens for prophylaxis against stress ulcers.

In summary, while these two prospective randomized trials on the use of sucralfate in the intensive care unit have suggested the inferiority of antacids, with or without added $\mathrm{H}_{2}$ blockers, it is not yet possible to conclude that agents that maintain the natural gastric acid barrier, such as sucralfate,

\section{REFERENCES}

1. Driks MR, Craven DE, Celli BR, et al. Nosocomial pneumonia in intubated patients given sucralfate as compared with antacids or histamine type 2 blockers: The role of gastric colonization. NEngl J Med 1987:317:1376-82

2. MacLean LD. Prophylactic treatment of stress ulcers: First do no harm. Can J Surg 1988:31:76-7.

3. Tryba M. Risk of acute stress bleeding and nosocomial pneumonia in ventilated intensive care unit patients: Sucralfate versus antacids. Am J Med 1987;83 (Suppl 3B):117-24

4. Bailey RW, Bulkley GB, Hamilton SR, et al. The fundamental hemodynamic mechanism underlying gastric 'stress ulceration' in cardiogenic shock. Ann Surg 1987;205:597-612.

5. Silen W, Merhav A, Simson JN. The pathophysiology of stress uker disease. World J Surg 1981;5:165-74

6 Stabile BE, Chang TM. Hiati IR, et al. Peptic ulcer complications are superior to $\mathrm{H}_{2}$ blockers in the development of stress lesions. It is also impossible to conclude that the risk of Gram-negative colonization in the development of pneumonia is higher. Studies need to be performed on larger numbers of patients and examination of the efficacy of treatment against elevated stress ulcers and clinically significant bleeding also need to be carried out. Control for the use of enteral feeding, the use of 'standard' doses of $\mathrm{H}_{2}$ blockers, and the use of infusion rather than bolus injection of these $\mathrm{H}_{2}$-receptor antagonists are also necessary for a successful study.

Finally, what was the impact of the presence of a nasogastric tube? A nasogastric tube was needed to administer the sucralfate and antacid. Did the presence of the nasogastric tube contribute to the occult blood present in the gastric aspirate of some patients, and did the presence of the nasogastric tube itself contribute to the colonization of the pharynx, sputum and stomach? First do no harm, but even before that, ensure that the agent selected for use is in fact effective and that the method of its delivery is itself doing no harm.

in high-risk patients. World J Surg 1987;11:345-9.

7. Borrero E, Mangolis IB, Bank S, Shulman N, Chardavoyne R. Antacid versus sucralfate in preventing acute gastrointestinal bleeding: A randomized trial in 100 critically ill patients. Am J Surg 1984:148:809-12.

8. Tryba M. Zevounou F. Torok M, Zeuz M. Prevention of acute stress bleeding with sucralfate, antacids or cimetidine: A controlled study with pirenzepine as a basic medication. Am J Med 1985,79 (Suppl 2C):55-61.

9. Borrero S, Bank S. Margolis I, Schulman ND. Chardavoyne R. Comparison of antacid and sucralfate in the prevention of gastrointestinal bleeding in patients who are critically ill. Am J Med 1985:79(Suppl 2C):62-4

10. Pingleton SK, Hinthorn DR, Liu C. Enteral nutrition in patients receiving mechanical ventilation: Multiple sources of tracheal colonization include the stomach. Am J Med 1986;80:827-32. 


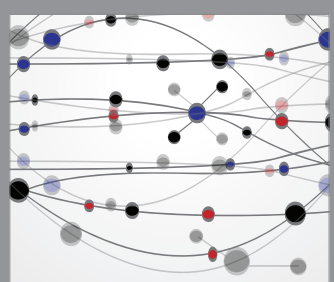

The Scientific World Journal
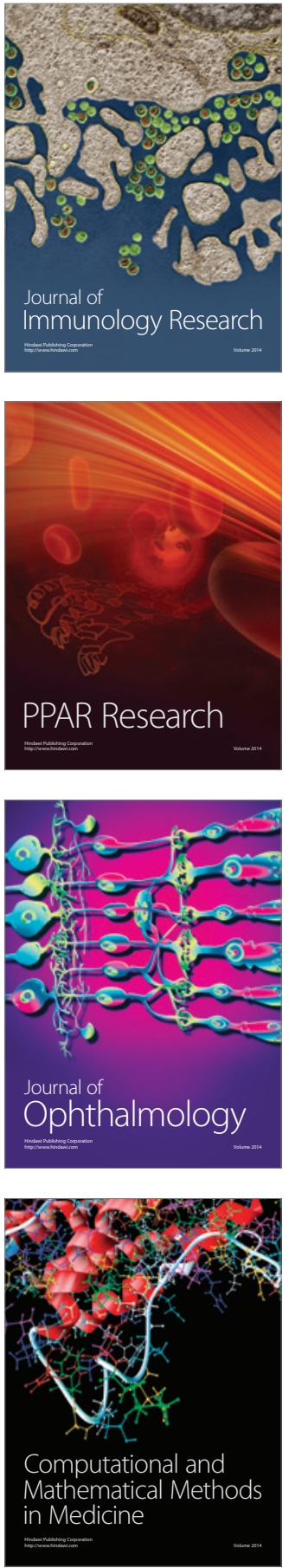

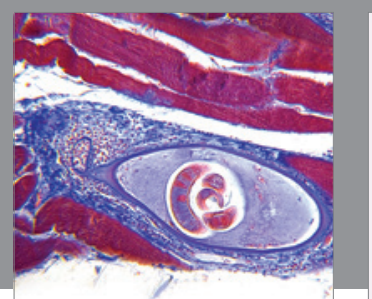

Gastroenterology Research and Practice

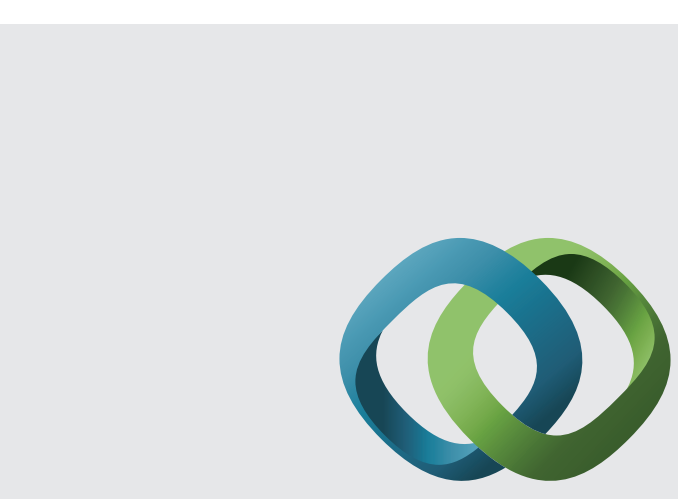

\section{Hindawi}

Submit your manuscripts at

http://www.hindawi.com
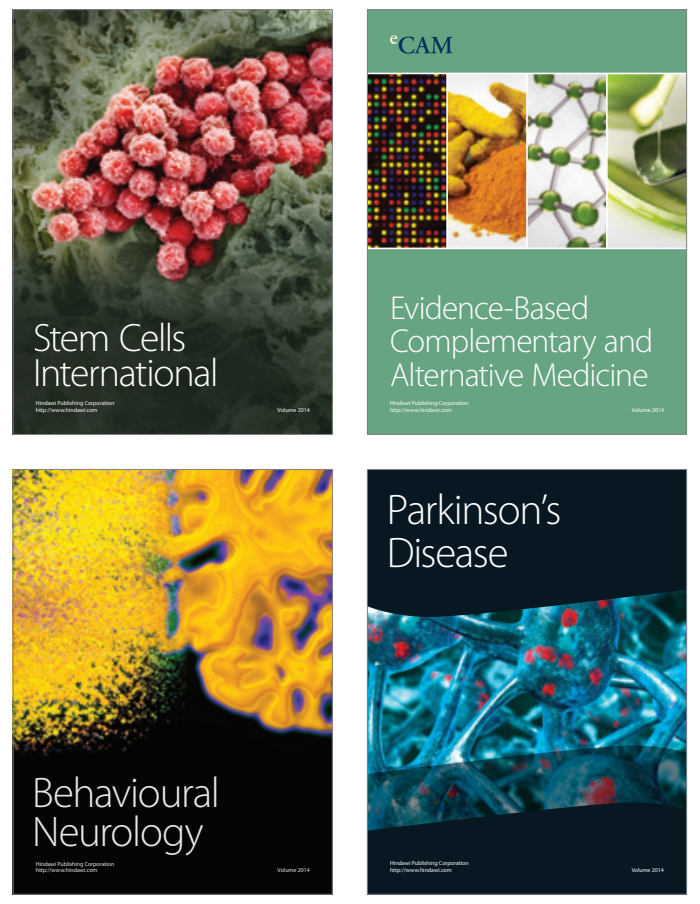
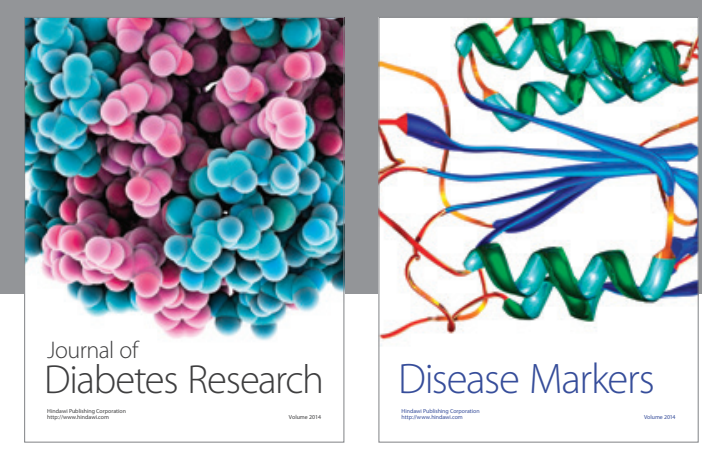

Disease Markers
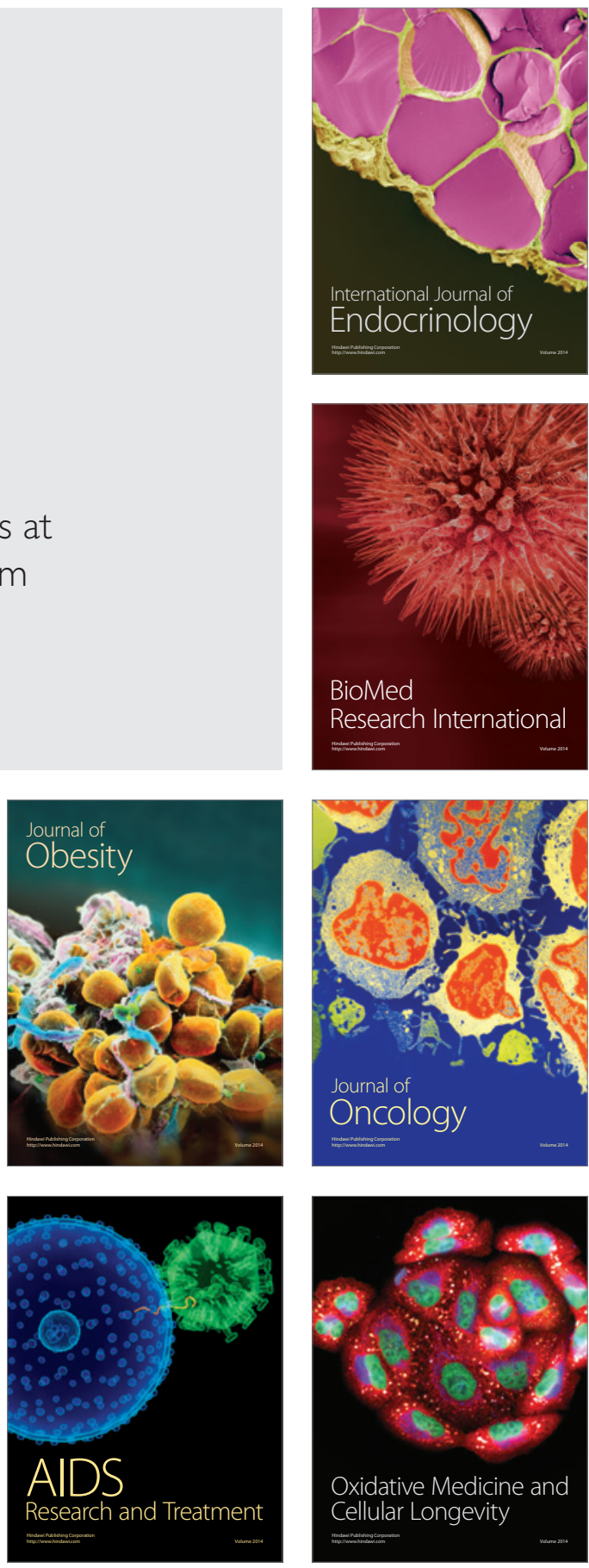